\title{
Utilization of Skin Flap for Reconstruction of the Genitalia after an Electric burn
}

\author{
Rodrigo B. Castro, Ana B. Oliveira, Luciano A. Favorito \\ Section of Urology and Center for Treatment of Burned Children, Souza Aguiar Municipal Hospital, \\ Rio de Janeiro, RJ, Brazil
}

\begin{abstract}
The objective of this article is to describe a case of an electric burn to the genitalia causing scrotal and testicular lesion, and the subsequent reconstruction using a skin graft.

The patient was a 10-year-old boy who was victim of an electric burn that harmed the genitalia. There was extended skin loss, penile, scrotal and partial testicular lesion. The treatment consisted of plastic surgery to reconstruct the genitalia with skin flaps grafted on the left thigh, the scrotum and the base of the penis. The patient recovered well and was discharged after two weeks. We concluded that in severe cases of electric burns to the genitalia, skin graft offer a good therapeutic option.
\end{abstract}

Key words: genitalia, male; burns, electric; reconstructive surgical procedures

Int Braz J Urol. 2006; 32: 68-9

\section{INTRODUCTION}

Genital burns are usually present when burns extend to more areas of the body. They are rarely isolated (1). In less than 5\% of cases of genitalia burn is the etiology electric (1). The most common late complications of genital burns are perineum and genitalia contracture, which can be avoided by excising scars and skin flaps (2). This article explores a case of electric burns to a child's genitalia with penile, scrotum and testicles lesion, reconstructed with skin graft.

\section{CASE REPORT}

A ten-year-old male patient was the victim of an electric burn to the genitalia and inferior members. The accident occurred when the patient was fly- ing a kite and it got caught up in a high-tension wire. He entered our hospital presenting second and third degree burns on $7.5 \%$ of his body surface (the left thigh, right leg and genitalia).

In examining the genitalia, we observed a loss of scrotal skin and exposition of the right testicle (Figure-1). We performed scrotal explorations and identified a small area of necrosis in the right caput epididymis and the right tunica albuginea. The necrotic tissue was debrided and the tunica albuginea and the epididymis were sutured.

Thirty days from admission, we chose to perform reconstructive plastic surgery of the genitalia using skin flaps to perform grafts in the left thigh, scrotum and at the base of the penis (Figure-2). The patient recovered well and was discharged after two weeks. The reconstruction aspect 4 months after surgery is demonstrated in Figure-3. 


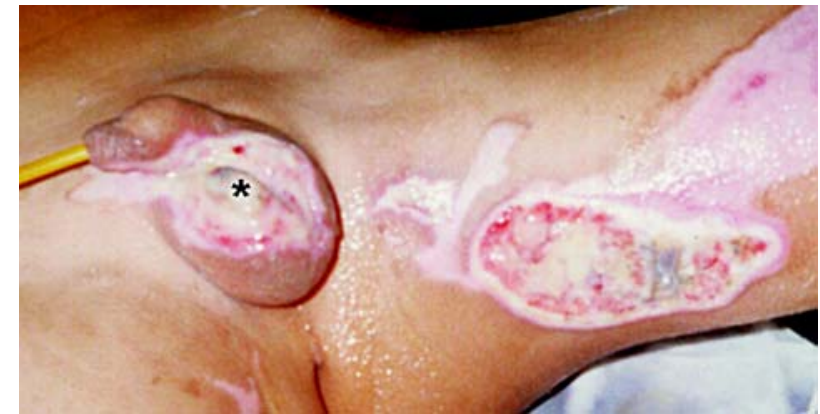

Figure 1 - Aspect of the genitalia 72 hours after the electric burn. Note the area of necrotic tissue in the scrotum. (*).

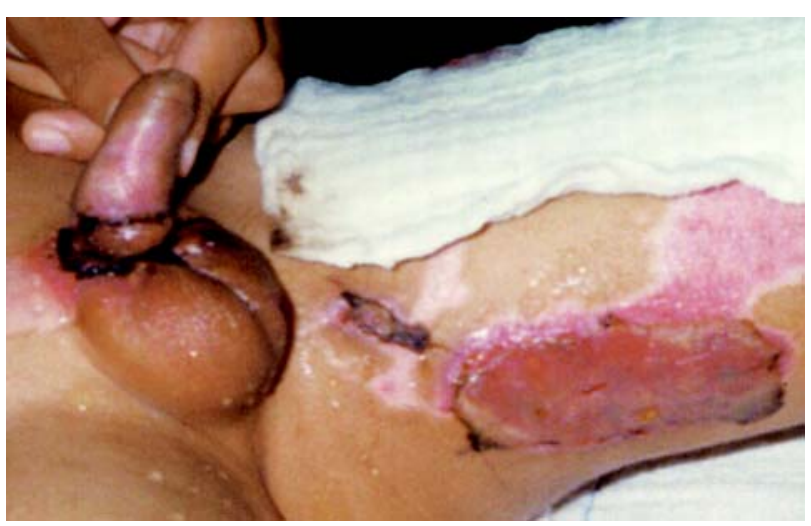

Figure 2-Aspect of the genitalia 14 days after skin flap.

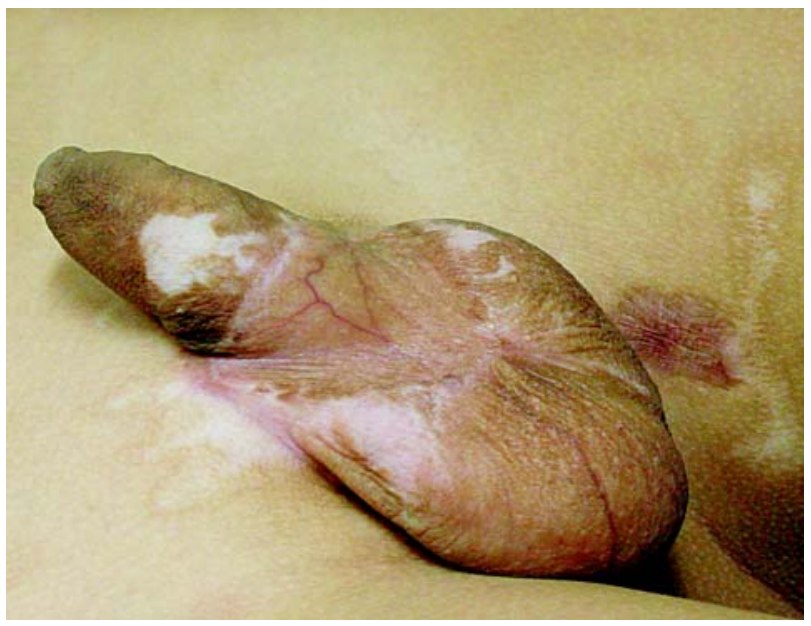

Figure 3 - Aspect of the genitalia 120 days after skin flap.

\section{COMMENTS}

Genital burns are generally caused by exposure to fire, burning water or chemical agents (3); electric burns of the genitalia are not that frequent in children (3). Treatment of burns to this area in chil- dren is usually conservative, usually consisting of topic applications of antimicrobials and silver sulfadiazine along with psychological support (3).

Debridement of wounds arising from burns and their early closure reduce the infection rate and lead to faster recovery with subsequently shorter hospital stay (1). The main complication from these burns is contraction of the wound, which generally occurs in more serious cases (3).

Testicular involvement, as in our case, indicates a more severe burn and this requires more aggressive handling as conservative treatment does not present good results (1). The use of skin grafts is recommended in cases where cicatrisation takes longer, or where there are more deep lesions, as in our case (3). We have concluded that in serious cases of electric burns to the genitalia, skin grafts offer a good therapeutic option.

\section{CONFLICT OF INTEREST}

None declared.

\section{REFERENCES}

1. Angel C, Shu T, French D, Orihuela E, Lukefahr J, Herndon DN: Genital and perineal burns in children: 10 years of experience at a major burn center. J Pediatr Surg. 2002; 37: 99-103.

2. Alghanem AA, McCauley RL, Robson MC, Rutan RL, Herndon DN: Management of pediatric perineal and genital burns: a twenty-year review. J Burn Care Rehabil. 1990; 11: 308-11.

3. Michielsen D, Van Hee R, Neetens C, LaFaire C, Peeters R: Burns to the genitalia and the perineum. J Urol. 1998; 159: 418-9.

Accepted after revision: July 25, 2005 